\title{
A new great wall: commissioning a new hospital in China
}

\author{
Authors: Patrick Chu ${ }^{\mathrm{A}}$ and Pearl Pai ${ }^{\mathrm{B}}$
}

A nationwide healthcare reform in China began in 2009, when the government injected GBP 85 billion to improve the healthcare coverage for its 1.3 billion population. Healthcare in China is primarily a market-based system, driven principally by demand, but the necessary supervision is relatively ineffective. There is a lack of trust between patients, who act as paying clients, and doctors, who often put the institution first, leading to frequent medical disputes. The University of Hong Kong Shenzhen Hospital is a joint venture between the city of Shenzhen and the University, with the mission to provide a new healthcare model in China. A clear process is in place to improve the clinical standard while a clean governance structure is set up. The hospital has ushered in many new initiatives. It is hoped that these will serve as a model for healthcare reform in China.

KEYWORDS: China, Hong Kong, health, reform, model

\section{Introduction}

In China, a nationwide health care reform has been underway since $2009^{1-4}$ in an attempt to modernise a publicly funded 'grass-roots' basic service amid much public discontent. ${ }^{5}$ Funded through a budget of GBP 85 billion, equal access is to be achieved by 2012 and universal coverage by 2020. The new University of Hong Kong Shenzhen Hospital (HKU-SZH) is a part of this evolution, representing a joint venture between the University of Hong Kong (HKU) and the municipal city of Shenzhen (SZ). This entirely new healthcare model aims to represent the best international standards and the strongest areas of Chinese healthcare, while ensuring cultural, social and political acceptability to the city and its people.

The principles of HKU-SZH are very much in line with those of the NHS: putting patients at the centre of attention, providing high quality treatment, offering a transparent, responsible, caring and clean structure of governance, informing patients, and developing and supporting staff. In this article, we will describe the challenges and the progress we have made in our hospital over the last two years. Despite the

Authors: ${ }^{A}$ Chief of services, Department of Medicine, University of Hong Kong Shenzhen Hospital; ${ }^{B}$ Consultant physician and nephrologist, Department of Medicine, University of Hong Kong Shenzhen Hospital, and honorary consultant, University of Hong Kong Queen Mary Hospital. difficulties and problems confronting Chinese healthcare, staff at the HKU-SZH have an immense commitment to working together to provide their patients with up-to-date and better healthcare. It is hoped that this new model of healthcare - ie promoting positive understanding and empathy between the public and the healthcare workers, with emphasis on clinical cost effectiveness, credibility, provision of training, research opportunities, job satisfaction and respect, supported by a responsible structure of governance - will enable the joint venture to succeed and realise its aims and aspirations.

\section{A brief overview of the city of Shenzhen}

Shenzhen is the fourth largest city in China, ${ }^{6}$ with a GDP of over GBP 135 billion. The city is $35 \mathrm{~km}$ north of Hong Kong, separated by the Shenzhen river. The city was designated as a Special Economic Zone in 1980 when China launched the first phase of its modernisation and economic reform programme. The estimated population of what was then regarded as a fishing port was reported to be about 30,000. Since then, the population has undergone exponential growth. By 2010, the population reached $10,357,938,90 \%$ of whom were migrants. They were young, with an average age of below 30 , and well educated (1,779,018 college-educated, 2,482,326 high-schooleducated, 4,562,697 educated to junior high level and 920,124 to primary level, according to 2011 Shenzhen municipal statistics). These vibrant human resources helped to lay the strong foundation on which the economic success of the city is built. The city started its development initially as major manufacturing centre and is now becoming one of the leading centres of information technology innovation, software development and financial services in China, and is now home to one of the biggest biotech company in the world.,

\section{A brief overview of the healthcare system debate in China}

The provision of good, safe, effective and comprehensive healthcare has long been regarded as a holy grail for the leaders of any country. It generates intense debate, the spectrum of which can vary from one of emotional and ideological engagement to detached analysis based solely on socioeconomic considerations. Specifically, the optimal means of funding such provision is unclear, as costs escalate at a rate that far exceeds the average growth of GDP in any country, even one growing as fast as China.

The Future Hospital Commission of the $\mathrm{RCP}^{9}$ highlighted some of the changes needed if the NHS is to cope with increasing demands from patients, escalating medical costs 
and the aspirations of its workforce. In China, healthcare reforms are if anything even more hotly debated, especially against the background of its impressive and unrivalled economic achievements since $1979,{ }^{2-5}$ which have bestowed an unprecedented improvement in living standards. By contrast, the availability of adequate healthcare has been fragmented and can vary widely from city to city, province to province, and above all from the urban to rural environment. ${ }^{4}$ At its core, the problem lies in the systems of funding employed. Prior to 1979, a Maoist model in which the state controlled both the demand for, and supply of, healthcare was in place. Since 1979, economic and political reforms have seen the setting up of a market-driven model where the allocation of resources is based on free market principles, ${ }^{10}$ although mainly embracing the concept of payment for items (but not services). On the positive side, this transformation resulted in a general improvement of standards of healthcare. However, given that China, by her own admission, is still a developing country, the application of free market principles has led to different people receiving different treatment, depending both on the ability to pay and geographical area. This has led to widespread public discontent. As a result, in 2009, the State Department launched an ambitious programme of reform, ${ }^{10,11}$ including universal insurance coverage, ${ }^{12}$ which will be discussed in subsequent sections of this paper.

\section{Funding models of healthcare in China and their associated problems}

In China public hospitals receive $87.6 \%$ of the total funding ${ }^{2}$ for medical care and therefore have market dominance. Thus, some $85 \%$ of beds are in public hospitals. However, the overall budget is generally regarded as grossly insufficient. Hospitals are also handicapped by supervision and control issues, impacting adversely on efficiency and quality. In general, the average funding supplied by the government for any public hospital is about $15 \%$ of its revenue and this is often targeted towards capital projects, leaving $85 \%$ of its operating budget reliant on its own sources of finance.

Under the present healthcare system, effective supervision is absent. Clinical services are provided on the basis of market demand for what are often 'trendy' medicines, rather than evidence-based care determined according to clinical need. Hospitals function publicly as clinical business units, which has led to over-prescription, over-treatment, over-investigation, over-regulation, favouritism, influence-peddling, corruption, shopping around, wasting of resources, medical disputes and even physical violence (see below).

Second, the pricing of medical services and the salaries of doctors have been set at a very low level, driving some to seek 'grey' income based on commissions for drug prescription, and so-called 'red packets of cash' for services provided. Such distorted behaviour and perverse incentives may lead to doctors becoming 'salesmen' for specific clinical services. ${ }^{13}$

Third, the allocation of medical resources and talents is largely channelled towards public hospitals, resulting in a weak system of primary care, especially in rural areas. Even in a wellestablished and modern metropolis like Shenzhen, there is a lack of primary care, leading to the inappropriate use of secondary care resources, and a draining effect on specialist expertise.

Fourth, regulations intended to improve clinical safety through the imposition of minimum standards (a necessary and rational development for China, with its large territories and widely differing levels of healthcare access among its cities, provinces and regions) have been over-ambitious and often poorly defined, understood and applied; arguably they have deterred innovation and restricted flexibility. For instance, the setup of a MR/CT scan needs four separate application processes and licenses. A cardiologist wishing to pursue interventional cardiology requires a license to do so, but it is unclear where or when the next license application or examination process will take place. This is also reflected in a lack of standardisation in postgraduate medical training on a national and even provincial basis. However, early reforms and pioneering work by some leading medical schools have already led to more structured and standardised undergraduate training; the challenge of extending these to postgraduate study remains. ${ }^{14,15}$

Finally, incidents in which disgruntled patients or relatives carry out acts of verbal or physical violence against medical or nursing staff are common in hospitals. Weapons may be used and fatalities have been reported. ${ }^{16,17}$ This is a phenomenon unique to China that generates widespread national and international attention. ${ }^{18}$ The reasons for such acts are varied and multifactorial, but reflect an underlying and deep-rooted lack of trust between patients and healthcare providers. Poor communication, lack of consultation time and unrealistic expectations that remuneration must lead to speedy diagnosis and treatment and then to full, prompt and perfect recovery from the illness have been roots of these problems. When these expectations fail to materialise, grievances, accusations, disputes, confrontations and even violence from the patients, their families and friends follow as a result in many cases. Reforms are therefore urgently needed and the programme launched by the State Department in $2009^{10,11}$ aims to make a number of fundamental changes (see Box 1).

With this broad background in our mind, we now turn our attention to the HKU-SZH.

\section{HKU-SZH - a new model of healthcare in China}

Given the continued urban expansion of Shenzhen and the growing demand for medical services in a city with a

\section{Box 1. Healthcare reforms initiated in 2009.}

Extension of basic medical insurance, leading towards a universal coverage model.

> Primary care provision (also known as grass-root health care reform) aiming at strengthening the primary care service, ${ }^{19}$ thus reducing the present heavy reliance on public hospitals, which currently provide almost $90 \%$ of services, nearly all of which are specialist services.

Public hospital reforms aiming at ending excessive drug sales, adopting evidence-based practice, and reducing over-investigation, over-prescription and over-regulation. (It is hoped that the present itemised payment will be replaced by capitation budget or diseaserelated budgets in which payment is based on services provided, or based on disease specific group, known also as 'diagnosis resource group'.) This packaged 'form of payment' will deter the overuse of investigations and prescription. Hopefully personal income gain or variation based on number of such billable items will cease. 
Fig 1. Hong Kong Shenzhen Hospital, 2014.

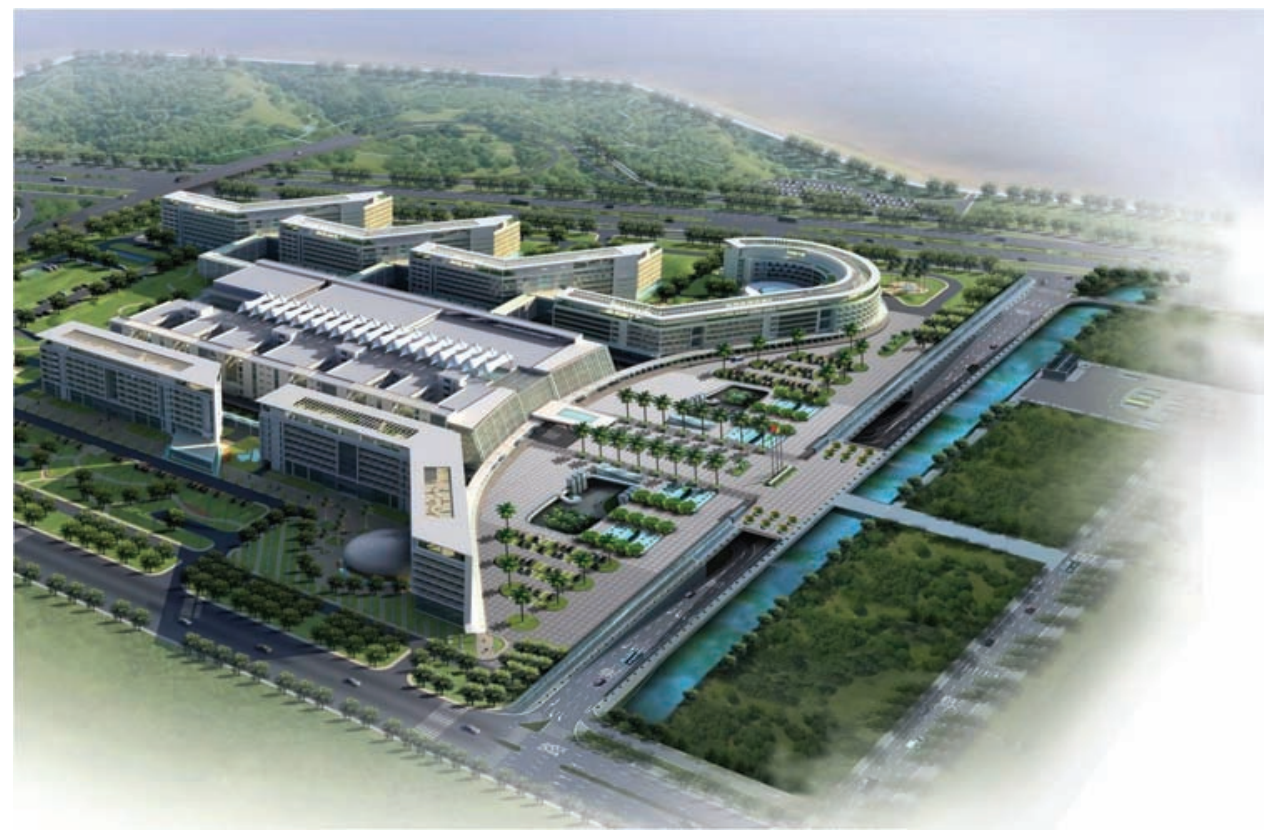

population of more than 10 million, the municipal city government started planning and building a new 'state of the art' hospital in 2007, with an investment of GBP 400 million. The municipal government and the University of Hong Kong (HKU) started discussions in 2009 and a co-operation agreement was signed in July 2011. The Li Ka Shing (LKS) Medical School of the University of Hong Kong was entrusted with the management of this new hospital. In the same year, the board of directors for HKU-SZH was appointed. The hospital started its phase 1 operation in July 2012, five years after its foundation was laid in 2007 (Fig 1).

The hospital was designed jointly by the US architect TRO Jung|Brannen and the Shenzhen City Design and Architecture Institute. It occupies a construction area of $367,000 \mathrm{~m}^{2}$ and has capacity for 8,000-10,000 outpatient visits per day. There are a total of 2000 beds, 650 beds of which are currently in use; the number of available beds will increase to 1500 by the end of 2015. In addition, the International Medical Centre started operating in the autumn of 2013, comprising its own outpatient and inpatient facilities with 238 beds when fully open. In the current phase 2 stage of development, there are about 2500 outpatient attendances daily, $250 \mathrm{~A} \& \mathrm{E}$ attendances daily and an average of 400 inpatients. There are a total of 36 'state of the art' surgical theatres, of which 12 are currently in regular use. Approximately 700 operations are carried out each month, including major neurosurgery, thoracic surgery and hepatic surgery. There is one cardiac catheter laboratory in operation. In total, 20 treatment centres are in service or being established, including centres for cardiovascular disease, respiratory disease, digestive disease, urogenital disease, endocrinology and metabolic disease, perinatology, neurology, orthopaedics, rehabilitation medicine, oncology, gynaecology, stomatology, ear nose and throat, paediatrics, immunology, haematology, plastic and reconstructive surgery, intensive care, anaesthesia and surgery, and A\&E. Further, the hospital aims to establish fully five areas of excellence to follow the University of Hong Kong.
They are oncology, orthopaedics and traumatology, in-vitro fertilisation and prenatal diagnosis, cardiovascular disease and organ transplantation. The first two areas are fully operational and it is expected that the other three areas will be ready in 2015.

The hospital is unique as a public healthcare facility in that it is funded by the City of Shenzhen while the managers and senior medical staff are employees directly appointed by HKU. The mission mandated by the City to the hospital is to improve clinical standards based on a clear governance structure, to enhance training and education for all staff and to initiate clinical and scientific research with the aim that the Hospital will become first class nationally and well-known internationally. To meet the challenges head on, the hospital put into practice the following six pioneering initiatives (Box 2).

\section{HKU-SZH: progress so far}

\section{Governance}

To develop effective clinical governance, the senior hospital management team and chiefs of service of each department

\section{Box 2. Pioneering initiatives at HKU-SZH hospital.}

> Triage system: primary care (family medicine) first, followed by specialist care.

> Transparent charging mechanism and finances; zero tolerance to 'red packets' or any form of grey income, while aspiring to the highest form of probity and professionalism.

$>$ Patient-centred, team-based clinical management.

$>$ Patient relations management, to deal with patient complaints or concerns without delay.

> Hospital-based indemnity, similar to the crown indemnity in the NHS system whereby liability rests with the hospital rather than the individual doctor. 
have introduced committees for safety and quality, incident reporting, research ethics, and complaints, which are all new initiatives to China. These efforts have been rewarded through accreditation by the Australian Council of Healthcare Standards (ACHS) in November 2013, with the hospital being the first in China to receive this certification. The hospital was commended by the Shenzhen government as the best run jointventure hospital and clinic in the city.

\section{Clinical activity}

Within two years of opening, the hospital has developed a full range of services. Unlike other Chinese medical institutions, which seldom operate a booking system, we have successfully introduced outpatient appointments, some $75 \%$ of which are made either online or by telephone. The on-site family medicine clinic service is fully backed up by secondary specialist services, almost always offering consultation on the same day. In addition, a chronic disease clinic has been set up by the family medicine department. These are all considered as new and innovative approaches in China. Patient numbers have steadily increased across all services with over $2800 \mathrm{OP}$ attendances daily, while in medicine, OP number has exceeded 600 per day. There is an average of 160 medical in-patients daily.

\section{Quality indicators}

Some outstanding quality indicators have been achieved by HKU-SZH, including being one of the hospitals with the lowest use of antibiotics per patient episode in China and the lowest wastage of blood products, and having one of the lowest rates of drug errors.

\section{Patient relationships}

An achievement commended by the ACHS relates to the manner in which the patient relation (PR) department handles complaints. Patients dissatisfied with services are advised to make a complaint either in person or by phone or e-mail. Some $90 \%$ of complainants receive a reply within 48 hours. All are discussed in a weekly meeting chaired by the deputy chief executive of administrative affairs, and subsequently followed up and action taken. The process is seen to be clear, transparent, and professional, thus avoiding many potential medical disputes, and the confrontation and violence that can result. As in the NHS, the majority of complaints involve poor communication, and an analysis of complaints is shared with all staff in a forum held every 6 months, so problems may be identified and improvements made. The incidence of complaints is remarkably low at less than $0.5 \%$.

\section{Commissioning new services}

To commission a new service in a hospital in China is a lengthy process. For example, the commissioning of our hospital dialysis service ${ }^{20}$ started in 2012 has involved many new government laws, rules and regulations being enacted to plug some past 'loopholes'. The tender and purchase of haemodialysis equipment, their installation, inspection and approval for operation, the staffing of the service and the processes for training, quality control and audit are outlined in Box 3.

\section{HKU-SZH: a new model of education and training}

In China, there is so far no structured, postgraduate training curriculum for doctors or nurses, nor are there clear processes for assessment or promotion in place. The training varies from city to city and province to province. The value of scientific contributions in the form of publications is often overplayed, regardless of merit, and plays an undue part in assessment for promotion. Intermediate and more advanced written examinations are used in different provinces for different specialties, as part of the requirement for promotion, but these are not standardised. Many doctors will pursue the gaining of a doctorate as a means for promotion rather than for intellectual satisfaction or enrichment.

Within the HKU-SZH, a learning environment where interactive debate and discussion are encouraged and valued is being introduced. In addition to twice-weekly professorial ward rounds undertaken by the HKU faculty staff, there is a fortnightly hospital grand round and a weekly Department of Medicine meeting. In the first two years of operation, the Department of Medicine held two CME-accredited courses in general internal medicine in addition to other specialty $\mathrm{CME}$ courses, and a course on dialysis with a practical demonstration is also planned. Doctors and nurses are given the chance to attach to various university departments for observation, and free places are made available for the HKU-SZH staff to attend medical meetings in the Queen Mary Hospital, HKU, and vice versa. In the UK, links are established with the Royal College of Physicians of Edinburgh using international web-streaming.

\section{HKU-SZH: clinical outcomes assessment}

Recently, the HKU-SZH dialysis centre was among 14 successful applications from the hospital to receive a grant provided by the Shenzhen Science and Technology Institute through open competition. The grant is given to find out whether a new model of managing haemolysis patients enhances treatment outcomes and quality of life. The hospital is also striking out to become an accredited training centre for family medicine and other specialties. We are currently introducing a structured curriculum for higher medical training akin to the one used by the Hong Kong College of Physicians. We are also adopting assessment tools based on the case-based discussion, miniclinical evaluation exercise and direct observation of procedure assessments used by the Joint Royal Colleges of Physicians Training Board.

\section{The Future Hospital Commission: relevance to HKU-SZH?}

The NHS has long held a role in leading and shaping the provision of healthcare, but in a number of areas China is working differently; both systems may learn and benefit from each other in a number of areas.

One such area is recognition of the potential role of primary care and generalists. The importance of primary care, or the lack of it, is nowhere better illustrated than in the metropolitan areas of China. Where functional primary care centres exist, they are usually privately run and serve largely non-Chinesespeaking expatriates from overseas. Moreover, the prevailing attitude among Chinese people is to insist on visiting hospital 
Box 3. Commissioning a new dialysis service.

Planning. A need for the dialysis centre and its equipment must be demonstrated and an application filed with the City. Once the application is approved, then a set tender process must be followed; the process is very protracted.

> Installation, inspection and approval. The first Chinese Standard of Operation Procedure (SOP) on dialysis was published in 2010.21 It refers to the standard of the facility, the qualifications of the staff, quality assurance, and compliance with international standards and guidelines. All new dialysis centres must comply with and satisfy the implementation guidelines before a license for their operation is granted. An on-site inspection is performed by clinical experts and a representative from the health authority to decide if all the requirements of the SOP have been met.

Staffing. Since 2010, all dialysis staff must possess the relevant certificates to work in a dialysis centre. Unlike in the UK, where increasingly nurses are given an extended or specialist role, nurses in China are assigned to a hospital department according to its needs; additional training is therefore often required when they are given a new assignment.

> Information and education. Patient information and education are often inadequate in China. Guidelines are poorly complied with by patients and clinicians alike. For this, free staff and patient education forums have been organised in HKU-SZH Hospital to highlight various diseases, their prevention and treatment. Nurses are given more responsibilities and opportunities to develop their own talents and build up their clinical expertise. Patients are increasingly taking an interest in their treatment.

> Social insurance payment. In China, all medical costs are contained in an official pricing book and dialysis is paid for per session. Despite social insurance cover, dialysis is not free in full, and even those patients entitled to receive it need to make a co-payment. Hospitals must receive approval from the Insurance Bureau as a designated haemodialysis centre eligible to apply and receive insurance payments before they get reimbursed. Again the application and its ultimate approval take time and effort.

Guidelines, pathways and quality standards. In the NHS and among nephrologists in the UK, comparative audit and self-reporting to the Renal Registry are taken for granted and recognised as a scheme designed to improve quality of care. In China there is no regulatory requirement to report dialysis outcomes. The Chinese SOP 2010 on dialysis refers to international guidelines such as KDOQI, and staff receive education on this, but with no enforcement. The guideline is referred to only when there is a critical incident. There is a lack of cooperation and mutual trust between different dialysis centres. Within our dialysis unit, we have put into place an environment of safe practice, clinical governance and quality assurance linked to dialysis therapy as demanded by international standards and audit cycles. Clinical pathways are being introduced in China by the government's desire to cap escalating medical cost. But at HKU-SZH we believe audits and clinical pathways should be developed and led by qualified doctors and the healthcare team. For example, at HKU-SZH, vascular catheterisation must only be undertaken under ultrasound guidance or screening, which is not the case in many other units.

specialists even for minor illnesses. In the UK, where primary care is established, we suggest secondary care must provide a supporting role and not become decoupled from it, as is the case in China. On clinical and economic grounds, chronic disease management should be based in primary care. At HKU$\mathrm{SZH}$, we have developed a comprehensive family medicine service and have geared towards training generalists to provide coordinated care for an ageing population.

Second, waiting times in China for consultation and treatment are kept to a minimum or else the patients seek immediate attention elsewhere, taking their source of funding with them. Consequently, access to nearly all specialist services can be obtained within days. Patients are truly making choices regarding where and when and by whom their treatment is delivered. This advantage is countered by the phenomenon of doctor or hospital 'shopping', and associated waste of resources. In the UK, patients are generally more passive. However, overall the current NHS debate about waiting times should encourage patients to be more proactive, like their Chinese counterparts, in making healthcare choices.

Third, the majority of doctors and nurses at HKU-SZH are extremely dedicated and committed to the hospital and all work towards a common goal. Overtime is not uncommon, and locums are not required. All mandatory lectures and exercises such as fire drills are well attended by staff from all sectors. It is a normal practice for educational seminars and forums to be held on weekends to minimise the impact on regular services. Sickness leave is less than $1 \%$.

Fourth, handovers and medical records in China are afforded great emphasis. The quality of case notes is one of the main determinants of the class and the grade of a hospital. Clinical notes are audited on a regular and frequent basis for their accuracy, completeness and timeliness by a dedicated hospital medical record department. All patients are given a detailed copy of summary at the time of discharge, akin to a discharge letter to the GP in the UK. Diagnoses are ICD coded in the discharge summary. All notes and summaries are typed by the resident doctor and must be checked and signed by another doctor. Secretaries are assigned to departments rather than to individual consultants. Each morning, there is a structured handover on each ward where the night staff and resident oncall report on all admissions and incidents from the previous night. The handover is attended by all ward doctors and nurses. All out-of-hours admissions and incidents are documented and signed in a handover book.

Fifth, in China there are strict rules that all urgent consultations must be seen within 30 minutes and, for nonurgent specialist consultation, within 24 hours of request. If an inpatient diagnosis is unclear after three working days, the attending clinicians are urged to call a multidisciplinary team meeting involving relevant clinical and diagnostic disciplines to discuss the case further, and these deliberations 
are fully documented in the notes and in a record book. Similarly, a mandatory mortality meeting must be held within seven working days of the death of a patient to provide an opportunity to fully review the case and identify learning points for the future. The meeting summary must be signed and kept in the mortality record book.

\section{Conclusion}

Healthcare provision in China is a free market; patients are paying clients and many doctors feel that they need to do what patients tell them to keep them. By contrast, the NHS is sustained on mutual trust and respect between doctors and patients. At HKU-SZH, we believe we can gain the trust of Chinese patients and serve them better by being honest, professional and empathetic.

The gap between China and the West is closing as more collaboration is taking place nationally and globally. These exchanges are already bringing benefits to patients and improving care. By developing health education, by promoting health, primary prevention and family medicine, by introducing structured training, assessment and appraisal systems and making promotion transparent, and by promoting mutual respect between doctor and patient, healthcare reforms in China will be effective and economically sustainable. Thus, in 2009 the Chinese government proposed an investment of GBP 85 billion (US $\$ 138$ billion) in healthcare reform for 2009$2011^{1-4}$ and holds out a promise of equal access and universal coverage by 2020 for its 1.39 billion people. ${ }^{12,19}$ It is another 'Great Wall' in the making, but unlike the original Great Wall, built to keep the northern invaders out of China, these reforms are looking beyond and welcome new ideas and reforms. For these reasons, we are immensely privileged and proud to take part in this mission.

\section{References}

1 CPC Central Committee. Opinions of the CPC Central Committee and the State Council on deepening the health care system reform. Available online at www.china.org.cn/government/scio-press-conferences/2009-04/09/content_17575378.htm [Accessed 22 November 2014].

2 Grail Research. China healthcare reform: past, present and future. www.integreon.com/pdf/Blog/Grail-Research-China-HealthcareReform_228.pdf [Accessed 20 December 2014].

3 Hougaard JL, Osterdal LP, Yu Y. The Chinese healthcare system: structure, problems and challenges. Appl Health Econ Health Policy 2011;9:1-13.
4 Brown RE, Píriz DG, Liu YY, Moore J. Reforming health care in China: historical, economic and comparative perspectives. University of Michigan, 2012. Available online at www.sites.fordschool.umich. edu/china-policy/files/2012/07/PP_716_Final_Policy_Paper_ Health-Final.pdf [Accessed 22 November 2014].

5 Daemmrich A. The political economy of healthcare reform in China: negotiating public and private. Springerplus 2013;2:448.

6 Shenzhen Statistical Yearbook. China Statistics Press, 2013.

7 Canadian Trade Commissioner Service. Focus on Shenzhen, China. Available online at www.tradecommissioner.gc.ca/eng/document. jsp [Accessed 22 November 2014].

8 Shenzhen Government Online. www.english.sz.gov.cn/economy/

9 Evans TW. The Future Hospital Journal of the Royal College of Physicians: Extending the mission. Future Hosp J 2014;1:3-4.

10 Duckett J. Economic crisis and China's 2009 health reform plan: rebuilding social protections for stability and growth? China Analysis, 2010. Available online at www.chinapolitik.de/studien/china_analysis/no_80.pdf [Accessed 22 November 2014].

11 Zhao LT and Huang YJ. China's blueprint for health care reform. East Asian Policy 2010;2:51-9.

$12 \mathrm{Yu} \mathrm{H}$. Towards universal health coverage: China lessons learned. WHO, 2013. Available online at www.wpro.who.int/china/mediacentre/releases/2013/20130605/en/ [Accessed 22 November 2014].

13 Wang H. A dilemma of Chinese healthcare reform: How to redefine government roles? China Econ Rev 2009;20:598-604.

14 Schwarz MR, Wojtczak A, Zhou T. Medical education in China's leading medical schools. Med Teacher 2004;26:215-22.

15 Hou J, Michaud C, Li Z, et al. Transformation of the education of health professionals in China: progress and challenges. Lancet 2014;384:819-27.

16 Hesketh T, Wu D, Mao L, Ma N. Violence against doctors in China. BMJ 2012;345:e5730.

17 Yang $\mathrm{T}$, Zhang H, Shen F, et al. Appeal from Chinese doctors to end violence. Lancet 2013; 382:1703-4.

18 Editorial. Violence against doctors: Why China? Why now? What next? Lancet 2014;383:1013.

19 Zhang XI Xiong Y, Ye J, et al. Analysis of government investment in primary healthcare institutions to promote equity during the threeyear health reform program in China. BMC Health Serv Res 2013; 13:114.

20 Pai P and Chan TM. Dialysis practice from the English NHS to the Orient. Clin Kid J 2013;6:554-5.

21 Chen MX. Blood purification standard operational procedure. People's Military Medical Press, 2010.

Address for correspondence: Professor Patrick Chu, MB ChB, FRCP(L), FRCP(E), FRCPath, 1 Haiyaun 1st Road,

Futian District, Shenzhen, China 518053.

Email: patrick.chu2@hku.szh.org 